\title{
OPEN Influence of biochemical diagnosis of growth hormone deficiency on replacement therapy response and retesting results at adult height
}

\author{
Giulia Rodari ${ }^{1,2 \bowtie}$, E. Profka², F. Giacchetti ${ }^{2}$, I. Cavenaghi², M. Arosio ${ }^{1,2}$ \& C. Giavoli ${ }^{1,2}$
}

Isolated growth hormone deficiency (IGHD) is the most frequent endocrinological disorder in children with short stature, however the diagnosis is still controversial due to the scarcity of reliable diagnostic criteria and pre-treatment predictive factors of long term-response. To evaluate recombinant growth hormone $(\mathrm{rGH})$ long-term response and retesting results in three different groups of children divided in accordance with the biochemical criteria of initial diagnosis. Height gain $(\triangle H T)$ at adult height (AH) and retesting results were evaluated in $57 \mathrm{rGH}$ treated children $(M=34,59.6 \%)$ divided into 3 groups according to initial diagnosis: Group $A(n=25)$ with max GH peak at stimulation test $<8 \mu \mathrm{g} / \mathrm{L}$, Group B $(n=19)$ between 8 and $10 \mu \mathrm{g} / \mathrm{L}$ and Group $C(n=13)$ with mean overnight $\mathrm{GH}<3 \mu \mathrm{g} / \mathrm{L}$ (neurosecretory dysfunction, NSD). Retesting was carried out in all patients after at least one month off therapy upon reaching the $A H .40 / 57(70.2 \%)$ patients were pre-pubertal at diagnosis and showed $\Delta H T$ of $1.37 \pm 1.00$ SDS, with no significant differences between groups $(P=0.08)$. Nonetheless, $46 \%$ patients in Group B showed $\triangle H T<1$ SDS (vs $13 \%$ and $12 \%$ in Group $A$ and $C$, respectively) and $25 \%$ children failed to reach mid-parental height (vs $6 \%$ and $0 \%$ in Group $A$ and $C$, respectively). At $A H$ attainment, IGHD was reconfirmed in $28 \%(7 / 25)$ and $10 \%(2 / 19)$ in Group $A$ and $B$, respectively. A reduction of diagnostic cut-off at GH stimulation tests could better discriminate between "good" and "poor responders" and predict the persistence of IGHD through transition. Group C response and the predictive value of baseline IGF-I SDS bring back to light NSD: should we consider an underlying hypothalamic derangement when the clinical presentation is strongly consistent with IGHD but pharmacological stimulation test is normal?

Growth hormone deficiency (GHD) is the most common endocrine disorder in children with short stature, with a reported prevalence of 1 in $4000^{1}$. Although relatively rare, a correct diagnosis is crucial, as recombinant growth hormone $(\mathrm{rGH})$ replacement therapy is highly effective in GHD, helping patients to achieve a normal adult height $(\mathrm{AH})$ according to their genetic potential ${ }^{2}$. On the other hand, a false positive diagnosis can lead to a significant wasted expenditure and unnecessary exposure to rare potential adverse effects.

According to the Consensus Guidelines ${ }^{2,3}$, the clinician should synthesize auxological, biochemical and neuroradiological data to attain GHD diagnosis. However, until now there are significant controversies, especially from the laboratory point of view. In fact, though growth hormone $(\mathrm{GH})$ provocative tests play a key role in the diagnostic process, measured GH concentration can vary significantly according to stimulation test or GH assay used. In order to distinguish between GHD and non-GHD patients, a cut-off of GH concentration should be established but to date, in the lack of any "gold standard test" for GHD diagnosis in childhood, any cut-off level seems somehow arbitrary. Moreover, GH secretion should be considered as a continuum from normality to severe GHD, implying a physiological overlap in peak GH concentrations between children with idiopathic short stature (ISS) and those with GHD. Due to these issues, separating the group of ISS from mild GHD can

${ }^{1}$ Endocrinology Unit, Fondazione IRCCS Ca' Granda Ospedale Maggiore Policlinico, Via Francesco Sforza 28, 20122 Milan, Italy. ${ }^{2}$ Department of Clinical Sciences and Community Health, University of Milan, Milan, Italy. ${ }^{\boxplus e m a i l}$ rodarigiulia@gmail.com 
be challenging: the reproducibility of provocative tests indeed is extremely poor and a great number of falsely abnormal responses are frequently observed even in normal children ${ }^{4}$.

Even considering auxological criteria first, diagnosis could be challenging. When GH provocative tests were first introduced in the 1960s, the biochemical diagnosis of GHD in childhood was defined for GH peak $<5 \mu \mathrm{g} /$ $\mathrm{L}^{5}$. Over time, this cut-off has been increased on the basis of very limited evidence to $10 \mu \mathrm{g} / \mathrm{L}^{6}$. Nonetheless, the latest Guidelines recognize that this threshold should be revised according to the advent of monoclonal antibody testing and newer standards that produce GH measurements approximately $40 \%$ lower than those obtained with the oldest immunoassays ${ }^{2,3,7,8}$. Therefore, the cut-offs for GHD should be reduced in the attempt to minimize the large number of false-positive results that lead to misclassify as deficient a child with normal GH secretion ${ }^{9-16}$.

Adjustment of this threshold should be defined locally by the paediatric endocrinology society specific to the country or region. In Italy, $\mathrm{rGH}$ prescription and reimbursement is regulated by Note 39 of the Italian Drugs Agency (AIFA). Its revision, in 2014, reducing the cut-off at provocative tests from 10 to $8 \mu \mathrm{g} / \mathrm{L}$, can be considered an effort in that sense ${ }^{17}$.

Nonetheless, there are rare patients who appear to have true GHD even though their stimulated GH peak exceeds traditional cut-offs or patients diagnosed having GHD in the presence of a peak GH between 8 to $10 \mu \mathrm{g} / \mathrm{L}$ showing a good response to rGH therapy.

As above mentioned, the reproducibility of stimulation tests is extremely poor ${ }^{18,19}$, consequently, in the past, the assessment of physiological GH secretion using the 12-h or the 24-h overnight GH profile with blood sampling every $20 \mathrm{~min}$ was considered a possible alternative for biochemical GHD diagnosis. Differently from provocative tests, $\mathrm{GH}$ profile has a superior reproducibility ${ }^{9,20-22}$ but a lower sensitivity, failing to diagnose $57 \%$ of GHD patients identified by GH stimulation tests ${ }^{20}$. The presence of an abnormal GH profile (reduced number of GH pulses and reduced pulse amplitude) along with low IGF-I concentration, auxology compatible with a diagnosis of GHD, bone age delay of at least 2 years and a normal GH stimulation test, define growth hormone neurosecretory dysfunction (NSD), condition probably due to hypothalamic derangement.

However, $\mathrm{rGH}$ therapy is no longer indicated in NSD, according to the strong recommendation against the use of spontaneous GH secretion in the diagnosis of GHD published in the Consensus Guidelines of $2016^{2}$.

Moreover, at the end of growth, up to $60-80 \%$ of patients diagnosed with isolated GHD (IGHD) re-test normal $^{23-27}$. It is unknown yet if this represents a form of transient GHD or a false positive diagnosis during childhood.

Given these open issues about biochemical diagnosis of IGHD in childhood, the aim of the present retrospective, single-centre study was to assess $\mathrm{rGH}$ long-term response (gain in height at $\mathrm{AH}$ ) and retesting results in three different groups of children divided in accordance with the biochemical criteria of initial diagnosis.

\section{Materials and methods}

Patients and study protocol. The study included 57 children $(\mathrm{M}=34,59.6 \%)$ treated with $\mathrm{rGH}$ at the Endocrinology Unit of Fondazione IRCCS Ca' Granda Ospedale Maggiore Policlinico of Milan until AH, from 1993 to 2019 for IGHD or NSD. At the time of diagnosis, all patients fulfilled the auxological criteria of height $(\mathrm{HT}) \leq-3$ SDS OR HT $\leq-2$ SDS with a growth velocity $(\mathrm{GV}) \leq-1$ SDS OR a GV $\leq-2$ SDS for the last year or $\mathrm{GV} \leq-1.5 \mathrm{SDS}$ for two consecutive years. At baseline age, mid-parental height (MPH), HT, weight, body mass index (BMI) and pubertal stage were recorded and SDS values for HT and MPH were calculated according to the Italian reference charts for Italian patients and the WHO growth charts for others $(n=6)$ according to "Growth calculator 4" by Italian Society of Pediatric Endocrinology and Diabetology (ISPED-SIEDP) available online ${ }^{28}$. Body mass index SDS was evaluated according to the WHO specific charts ${ }^{28}$. Before rGH treatment, bone age was calculated according to the standards of Tanner-Whitehouse ${ }^{29}$ and a brain MRI was performed in every patient. All patients underwent two of the following GH stimulation tests: clonidine, arginine, glucagon or insulin tolerance test (ITT). In cases of suspected NSD with normal response to GH stimulation test, an overnight $\mathrm{GH}$ profile $(12 \mathrm{~h}$ ) was carried out with samples taken with a short intravenous catheter every 30 min from 20.00 to $08.00^{9,30}$.

In order to avoid biases due to late diagnosis and treatment, $\mathrm{AH}$ response was analysed separately in the 40/57 patients who were pre-pubertal at rGH start.

At AH attainment, each patient was retested with GHRH + arginine $(n=54)$ or ITT $(n=3)$ after at least one month off therapy. The lowest GH cut-off limit at retesting considered normal was $19 \mu \mathrm{g} / \mathrm{L}$ for the combined test and $6 \mu \mathrm{g} / \mathrm{L}$ for ITT $^{31,32}$.

Patients with other pituitary hormone deficiencies, GHD secondary to neoplasia, irradiation or pituitary stalk interruption syndrome were excluded from the study as well as patients born small for gestational age or with underlying chronic diseases (i.e. coeliac disease).

According to biochemical diagnostic criteria of Note AIFA 39, until 2009 rGH therapy could be reimbursed to children with either two abnormal provocative tests with a cut-off of $10 \mu \mathrm{g} / \mathrm{L}$ or NSD, from $2009 \mathrm{rGH}$ treatment was no more reimbursed in NSD, while in 2014 GHD the cut-off was lowered to $8 \mu \mathrm{g} / \mathrm{L}$. In line with those changes, our patients were divided into three groups: Group A $(n=25)$ of IGHD patients with max GH peak at both stimulation tests $<8 \mu \mathrm{g} / \mathrm{L}$, Group B $(\mathrm{n}=19)$ of IGHD patients with a max GH peak between $8 \mu \mathrm{g} / \mathrm{L}$ and $10 \mu \mathrm{g} / \mathrm{L}$ at least at one test and Group C $(\mathrm{n}=13)$ classified as NSD according to overnight GH profile (mean $\mathrm{GH}<3 \mu \mathrm{g} / \mathrm{L}$ ) but peak $\mathrm{GH}>10 \mu \mathrm{g} / \mathrm{L}$ at provocative test ${ }^{33,34}$.

Poor response at $\mathrm{AH}$ was defined in the presence of total gain $\Delta \mathrm{HT}<1 \mathrm{SDS}^{35}$. Mid-parental height target achievement was defined as AH-MPH $>-2$ SDS.

All procedures performed in this study were in accordance with the ethical standards of the institutional research committee and with the 1964 Helsinki declaration and its later amendments or comparable ethical 


\begin{tabular}{|l|l|l|l|l|l|l|}
\hline & Patients (57) & Group A (25) & Group B (19) & Group C (13) & Sign & N \\
\hline CA (years) & $11.9(1.9-17.1)$ & $12.9(2.8-15.2)$ & $11.6(6.4-17.1)$ & $10.5(1.9-15.7)$ & $P=0.12$ & 56 \\
\hline MPH (SDS) & $-0.86(0.82)$ & $-0.76(0.90)$ & $-0.82(0.74)$ & $-1.12(0.77)$ & $P=0.47$ & 53 \\
\hline HT (SDS) & $-2.48(0.77)$ & $-2.36(0.86)$ & $-2.43(0.64)$ & $-2.82(0.72)$ & $P=0.26$ & 53 \\
\hline BMI (SDS) & $0.11(1.36)$ & $0.14(1.46)$ & $-0.08(1.24)$ & $0.44(1.41)$ & $P=0.62$ & 52 \\
\hline IGF-I (SDS) & $-1.68(0.86)$ & $-1.67(0.87)$ & $-1.72(0.63)$ & $-1.61(1.17)$ & $P=0.94$ & 53 \\
\hline
\end{tabular}

Table 1. Baseline characteristics expressed as mean (SD) or median (min-max). $C A$ chronological age, $M P H$ mid-parental height, $H T$ height, $B M I$ body mass index, IGF-I insulin-like growth factor-I.

standards. Informed written consent was obtained from all study subjects and, under 18 years of age, from parents and/or a legal guardian.

Assay methods. From 1992 to October 2007, a two-site monoclonal immunofluorometric assay method (AutoDelfia kit, Wallac, Inc. OY, Turku, Finland) was used. The sensitivity of this method was $0.01 \mu \mathrm{g} / \mathrm{L}$ and intra- and interassay coefficients of variation were $2 \%$ and $1.7 \%$, respectively. After October 2007 , GH was assayed with a chemiluminescence method (Immulite 2000, Siemens Medical Solutions Diagnostics, Los Angeles, CA) with a detection limit of $0.01 \mu \mathrm{g} / \mathrm{L}$. In both cases, the standards were calibrated to the first World Health Organization International Reference Preparation (code 80/505). After the second semester of 2010, the standards of the Immulite method were calibrated to the WHO International Standard IS 98/574.

Serum IGF-I concentrations were measured by commercial RIA kits starting from 1985 . According to the RIA assay used before 1996 (Incstar, Stillwater, MN), the removal of binding proteins was obtained by acidification and subsequent filtration on ODS C18 cartridges. The intra- and interassay coefficients of variation were 15 and $16 \%$, respectively. Afterwards and until 2008, IGF-I levels were assessed by the commercial radioimmunometric assay kit of Mediagnost (Tübingen, Germany). The separation of IGF-I from binding proteins was obtained by acidification in IGF-II excess, and IGF-II cross-reactivity was less than $0.05 \%$. The intra- and interassay coefficients of variation were 3.2 and $8.9 \%$, respectively. After 2008, IGF-I levels were measured by a chemiluminescent immunometric assay (Immulite 2000 IGF-I; Siemens Medical Solutions Diagnostics, Los Angeles, CA), with an intra- and interassay coefficient of variation of 2.9 and $7.4 \%$, respectively. Standards used for calibration were IRR 87/518 to April 2017 and IS 02/254 from May 2017. The values were compared with those from an appropriate age- and sex-adjusted range for each kit and expressed in standard deviation scores (SDS).

Statistical analysis. Statistical analysis was performed using SPSS version 26 statistical package (SPSS IBM, New York, USA).

Descriptive analysis was used to characterise the study population (mean and standard deviation for normally distributed continuous variables, median and range for others). To compare two normally distributed continuous variables, Student's t test was used; otherwise, a Mann-Whitney test was employed. In order to compare the three groups at baseline and at $\mathrm{AH}$, for normally distributed continuous variables was performed one-way ANOVA test, otherwise Kruskal-Wallis test was used. Categorical variables were compared with the $\chi^{2}$ or Fisher's exact test. Pearson's correlation coefficient was used as a measure of the linear relationship between continuous variables. Multiple regression analysis was used to assess the importance of various auxological, treatment and GH secretion variables in the prediction of growth response (age at start, HT SDS, MPH difference, BMI SDS and IGF-I SDS at baseline, GH peak, rGH dose during the first and the last year of therapy and duration of treatment). Stepwise removal was performed with exclusion criterion $P>0.10$. Statistical significance was defined as a two-sided $P<0.05$.

Ethical approval. Ethical approval was waived by the local Ethics Committee of Fondazione IRCCS Ca' Granda Ospedale Maggiore Policlinico of Milan. In view of the retrospective nature of the study and all the procedures being performed were part of the routine care.

\section{Results}

Baseline characteristics. Median age at GHD diagnosis was 11.9 years (range 1.9-17.1 years), being not significantly different in the three groups $(P=0.12)$. Among them, $34(59.6 \%)$ patients were males $(13 / 25$ in Group A, $13 / 19$ in Group B and 8/13 in Group C, respectively. $P=0.48)$. Bone age was available for $43 / 57$ patients and was $9.0 \pm 3.1$ years, not significantly different in the three groups $(P=0.07)$. The majority of them was prepubertal $(40 / 57,70.2 \%)$ at rGH start.

Baseline characteristics were not different in the three Groups as stated in Table 1.

At GH stimulation test (arginine, glucagon, ITT and clonidine), median max GH peak was $5.5 \mu \mathrm{g} / \mathrm{L}$ (range $0.1-7.9 \mu \mathrm{g} / \mathrm{L}$ ) in Group A and 8.6 $\mu \mathrm{g} / \mathrm{L}$ (range 8.0-9.9 $\mu \mathrm{g} / \mathrm{L}$ ) in Group B $(P<0.0001$ ). In Group C mean GH at overnight profile was $1.7 \pm 0.9 \mu \mathrm{g} / \mathrm{L}$ (range $0.5-2.8 \mu \mathrm{g} / \mathrm{L}$ ).

Brain MRI was normal in $61 \%$ patients (35/57), whereas $15 / 57$ patients (26\%, 7 Group A, 5 Group B, 3 Group C, respectively) had an anterior pituitary hypoplasia, 6/57 (11\%, 5 Group A, 1 Group B, respectively) a partial empty sella and $1 / 57$ belonging to Group A (2\%) a pars intermedia cyst. 


\section{AH-Ht baseline}

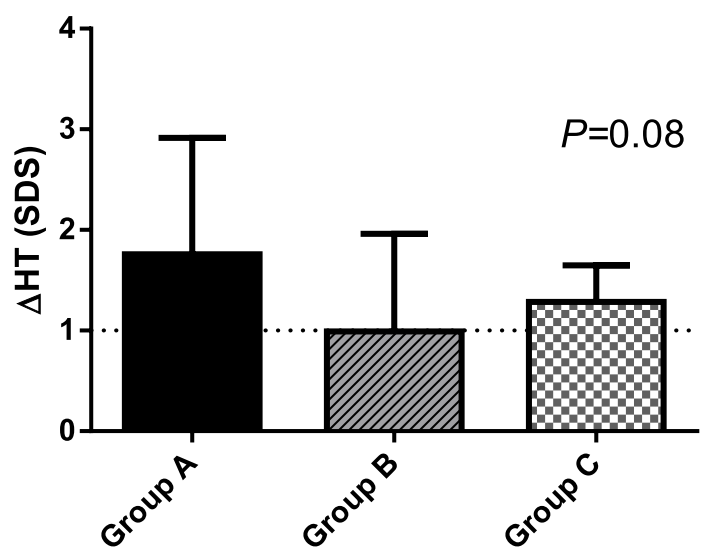

Figure 1. Height gain $(\Delta \mathrm{HT})$ at adult height $(\mathrm{AH})$ in the three groups of pre-pubertal patients.

\begin{tabular}{|l|l|l|l|l|l|l|}
\hline & Patients (40) & Group A (17) & Group B (13) & Group C (10) & Sign & n \\
\hline AH (cm) & $163.4(9.5)$ & $166.2(9.7)$ & $161.6(9.8)$ & $160.9(8.3)$ & $P=0.28$ & 40 \\
\hline AH (SDS) & $-1.22(0.93)$ & $-0.89(0.99)$ & $-1.54(0.95)$ & $-1.38(0.66)$ & $P=0.14$ & 40 \\
\hline MPH (SDS) & $-0.81(0.87)$ & $-0.77(1.0)$ & $-0.73(0.79)$ & $-0.99(0.80)$ & $P=0.77$ & 37 \\
\hline$\Delta$ HT at AH (SDS) & $1.37(1.0)$ & $1.95(-0.39$ to 3.79$)$ & $1(-0.41$ to 2.9$)$ & $1.34(0.51-1.7)$ & $P=0.08$ & 36 \\
\hline AH-MPH (SDS) & $-0.41(1.15)$ & $-0.05(-3.01$ to 1.42$)$ & $-0.5(-2.73$ to 0.77$)$ & $-0.24(-1.95$ to 1.87$)$ & $P=0.23$ & 37 \\
\hline Dose AH (mg/kg/day) & $0.026(0.099)$ & $0.03(0.011)$ & $0.022(0.008)$ & $0.022(0.006)$ & $P=0.07$ & 32 \\
\hline
\end{tabular}

Table 2. Response to treatment (pre-pubertal) given as mean (SD) or median (min-max). $A H$ adult height, $M P H$ mid-parental height, HT height.

Growth hormone therapy was started at a mean dose of $0.028 \pm 0.007 \mathrm{mg} / \mathrm{kg} / \mathrm{day}$, being higher in Group C $(0.027 \pm 0.007,0.025 \pm 0.006,0.035 \pm 0.005 \mathrm{mg} / \mathrm{kg} /$ day, in Group A, B and C respectively, $P=0.002)$, even if in the replacement range.

Adult height and retesting results. After a mean time of treatment of $4.7 \pm 2.7$ years (not significantly different in the three groups, $P=0.16$ ), the mean AH was $163.3 \pm 9.0 \mathrm{~cm},-1.22 \pm 0.89$ SDS, not significantly different in the three groups (median AH of $-0.90,-1.29$ and -1.65 SDS in Group A, B and C, respectively, $P=0.14)$ with an overall height gain $(\Delta \mathrm{HT})$ at AH of $1.22 \pm 1.04$ SDS $(P<0.0001$ vs baseline; median $\Delta \mathrm{HT}$ of $1.17,1.0,1.31$ SDS in Group A, B and C, respectively, $P=0.27$ ). At AH, the MPH difference (MPH SDS-AH SDS) was $-0.35 \pm 1.05$ SDS, not significantly different in the three groups $(P=0.64)$. During treatment, $\mathrm{rGH}$ titration was performed according to IGF-I SDS and growth response. Mean $\mathrm{rGH}$ dose at AH was $0.026 \pm 0.009 \mathrm{mg} / \mathrm{kg} /$ day with no difference in the three groups $(P=0.08)$.

In the subgroup of pre-pubertal patients (Group A: $n=17$, Group B: $n=13$, Group C: $n=10$ ), after a mean time of therapy of $5.7 \pm 2.7$ years $(P=0.17)$, the mean AH was $163.4 \pm 9.5 \mathrm{~cm},-1.22 \pm 0.93$ SDS $(-0.89 \pm 0.99$; $-1.54 \pm 0.95 ;-1.38 \pm 0.66$ SDS in Group A, B and C, respectively, $P=0.14$ ) with an overall $\Delta H T$ at AH of $1.37 \pm 1.0$ SDS (1.95 SDS, 1 SDS and 1.34 in Group A, B and C respectively, $P=0.08$, showed in Fig. 1). Detailed results are stated in Table 2.

Using the long-term efficacy criteria of Deodati and Cianfarani ${ }^{35}$, Group B showed the highest percentage of "poor responders" with $46 \%$ patients with $\triangle \mathrm{HT}$ AH $<1$ SDS (vs $13 \%$ and $12 \%$ in Group A and C, respectively, showed in Fig. 2) and with 25\% children not reaching MPH (vs 6\% and $0 \%$ in Group A and C, respectively, showed in Fig. 3).

Moreover, comparing mean AH SDS with mean MPH SDS, the difference was statistically significant only for patients of Group B ( $P=0.03$, shown in Fig. 4).

Height gain at AH was negatively correlated with HT SDS at baseline ( $P=0.001$, showed in Fig. 5a), MPH difference $(P=0.004$, showed in Fig. 5b), IGF-I SDS at baseline $(P=0.003$, showed in Fig. $5 c)$ and positively correlated with rGH dose both during the first year of treatment $(P=0.032)$ and at AH $(P=0.006$, Table 3). At backward stepwise regression model, the most important predictive factors of $\Delta \mathrm{HT}$ at AH were low HT SDS at baseline $(B-0.64 \pm 0.22, P=0.007)$ and $\mathrm{rGH}$ dose at $\mathrm{AH}(B 47.4 \pm 16.3, P=0.006)$.

At $\mathrm{AH}$ attainment, GHD was reconfirmed in $28 \%(7 / 25), 10 \%(2 / 19)$ and $8 \%(1 / 13)$ patients in Group A, B and $\mathrm{C}$, respectively $(P=0.18)$. Among patients with persistent GHD, 8/10 (80\%) have minor abnormalities of the pituitary region: $2 / 10$ a partial empty sella and 6/10 an anterior pituitary hypoplasia. Median age at diagnosis of 


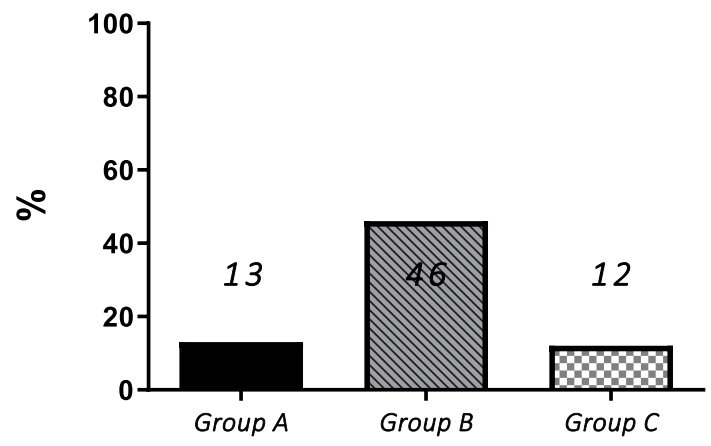

Figure 2. Percentage of "poor responders" according to $\Delta \mathrm{HT}<1$ SDS in the three groups.

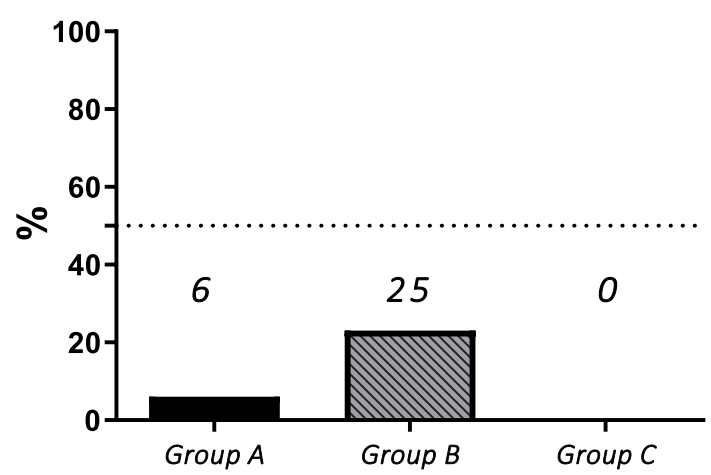

Figure 3. Percentage of patients who failed to achieve mid-parental height (MPH) target in the three groups.

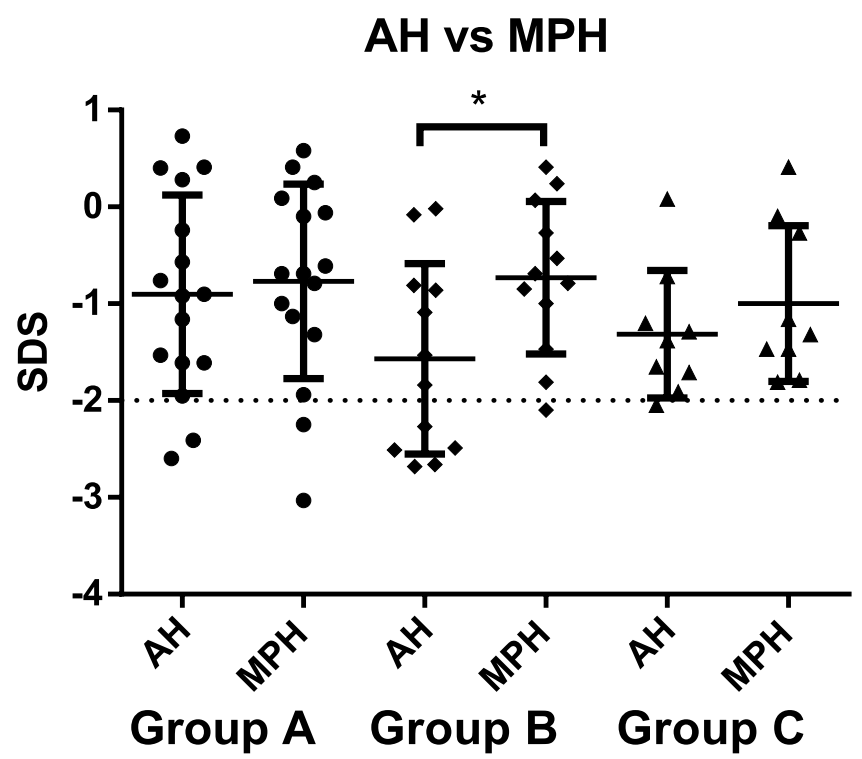

Figure 4. Mean adult height (AH) SDS and mean Mid-parental height (MPH) difference in the three groups. *: $P=0.03$.

patients with persistent GHD was 12.5 years (range 2.8 to 15.5 years, vs median age in non-persistent GHD of 11.8 years, $P=0.71$ ) and mean IGF-I SDS -1.13 SDS (range -2.85 to 0.75 SDS, vs median IGF-I SDS -0.75 in non-persistent GHD, $P=0.54)$. 
a HT baseline (SDS)

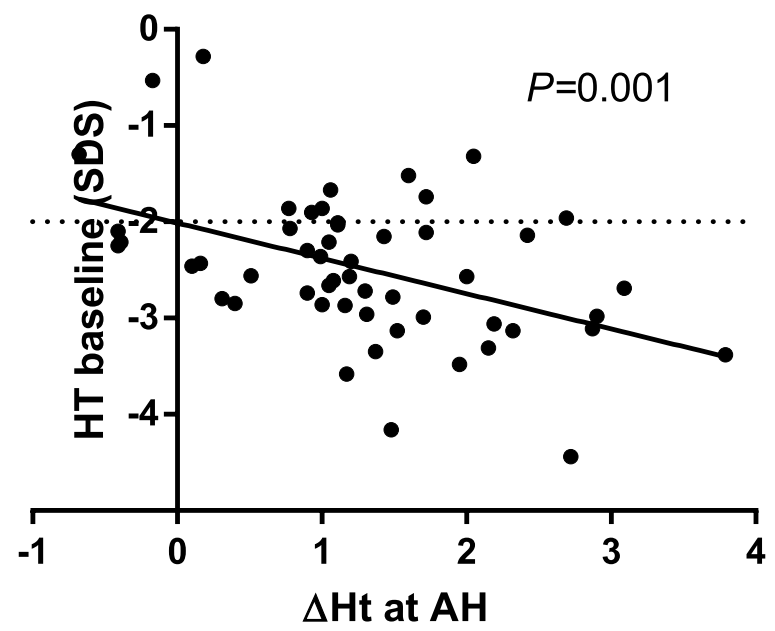

b $\quad \Delta$ HT baseline - MPH (SDS)

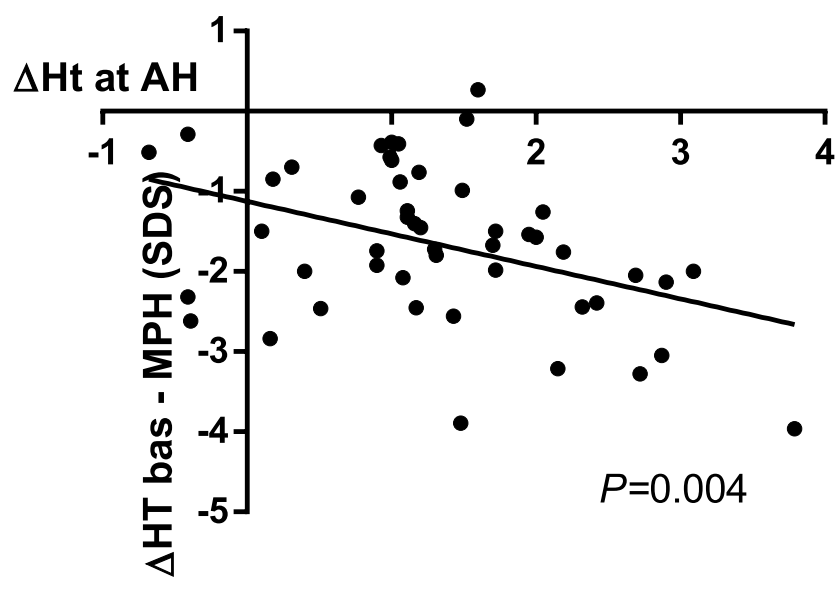

C

IGF-I SDS

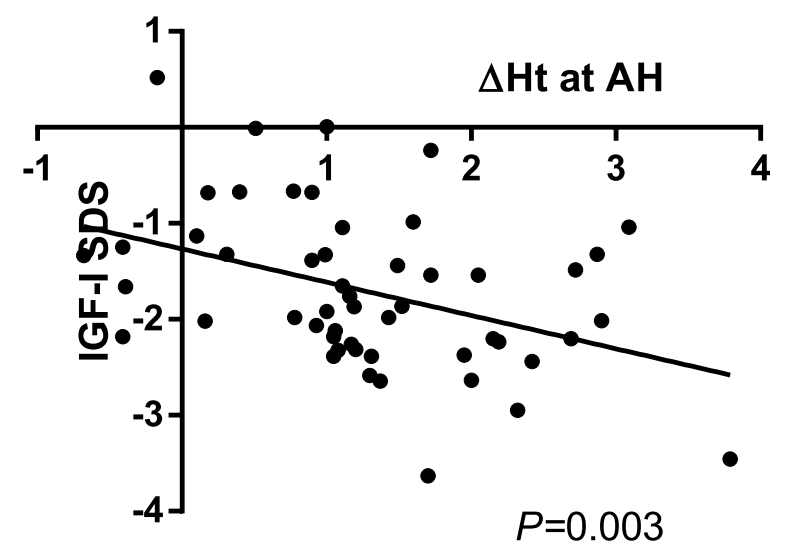

Figure 5. Correlations between height gain $(\Delta \mathrm{HT})$ at adult height $(\mathrm{AH})$ and (a) height SDS at baseline; (b) mid-parental height (MPH) difference at baseline expressed as height SDS; (c) insulin-like growth factor-I (IGFI) at baseline. 


\begin{tabular}{|l|l|l|l|}
\hline$\Delta$ HT at $\mathrm{AH}$ & $\boldsymbol{P}$ value & $\boldsymbol{r}$ & $\boldsymbol{R}^{\mathbf{2}}$ \\
\hline IGF-I (SDS) & 0.003 & -0.398 & 0.159 \\
\hline HT baseline (SDS) & 0.001 & -0.456 & 0.208 \\
\hline$\Delta$ HT baseline-MPH (SDS) & 0.004 & -0.405 & 0.164 \\
\hline Dose $\mathrm{rGH}$ I year (mg/kg/day) & 0.032 & 0.321 & 0.103 \\
\hline Dose $\mathrm{rGH}$ at $\mathrm{AH}(\mathrm{mg} / \mathrm{kg} /$ day) & 0.006 & 0.414 & 0.171 \\
\hline
\end{tabular}

Table 3. Regression analysis data on correlations between height gain at adult height and other variables. $H T$ height, $A H$ adult height, IGF-I insulin-like growth factor-I, MPH mid-parental height, $r G H$ recombinant growth hormone.

\section{Discussion}

To the best of our knowledge this is the first paper comparing long-term rGH outcomes $(\mathrm{AH}, \Delta \mathrm{HT}$ at $\mathrm{AH}$ and $\mathrm{AH}-\mathrm{MPH}$ ) between GHD children with max peak $\mathrm{GH}$ at diagnosis $<8 \mu \mathrm{g} / \mathrm{L}$ and between 8 and $10 \mu \mathrm{g} / \mathrm{L}$, including also patients with abnormal overnight GH profile. The main results of the present study are that children with lower GH peak at diagnosis have a better response to $\mathrm{rGH}$ treatment and more probability of persistent GHD.

To date, there are no new data regarding the normal range for stimulated GH levels and no randomized controlled studies that correlate GH provocative testing results with subsequent long-term efficacy of rGH treatment. Available evidence is only derived from short-term response (in the first few years) and consistently shows some predictive value of $\mathrm{GH}$ peaks $<10 \mu \mathrm{g} / \mathrm{L}^{36-38}$. A recent retrospective study on short- and long-term response to treatment in GHD Italian patients reported an higher gain in height at AH in patients with severe GHD defined for $\mathrm{GH}$ peak $<5 \mu \mathrm{g} / \mathrm{L}(1.85 \pm 0.6 \mathrm{SDS})$ than in patients with peak GH between 5 and $10 \mu \mathrm{g} / \mathrm{L}(1.39 \pm 0.6 \mathrm{SDS})^{39}$.

As abovementioned, with the advent of monoclonal antibody GH measurement and newer standards, the cutoffs for GH deficiency should be probably reduced to minimize false-positive results that can mistakenly classify as deficient a child with ISS. This change has already occurred in some European countries where the threshold has been reduced to $7 \mu \mathrm{g} / \mathrm{L}$. Adjustment of this cut-off should be defined locally by the paediatric endocrinology society of each country ${ }^{3}$. In Italy, the revision of Note 39 in 2014, reducing the threshold at provocative tests from 10 to $8 \mu \mathrm{g} / \mathrm{L}$, can be considered a first attempt in that sense. However, so far no study has assessed the long-term outcomes differences between patients with $\mathrm{GH}$ peak $<8 \mu \mathrm{g} / \mathrm{L}$ or between 8 and $10 \mu \mathrm{g} / \mathrm{L}$, in order to support the reduction of the diagnostic cut-off.

According to our results, the reduction of GH peak cut-off may help to identify children that will benefit from rGH therapy, discriminating between "good" and "poor responders" not only in terms of median $\Delta \mathrm{HT}$ at $\mathrm{AH}$ (i.e. percentage of patients "poor responders" according to Deodati \& Cianfarani criteria), but also in the percentage of patients reaching $\mathrm{MPH}$, an aspect to take into consideration in an expensive subcutaneous daily injective therapy as $\mathrm{rGH}$.

In Group B, indeed, $46 \%$ patients showed a dissatisfactory growth response at $\mathrm{AH}$, with $25 \%$ "true nonresponders" not reaching MPH target at AH. According to the revised biochemical criteria for GHD diagnosis, those patients are now classified as ISS.

Noteworthy, from 2003 on, rGH treatment has been approved from the Food and Drug Administration (FDA) in the United States for children with ISS with $\mathrm{HT}<-2.25$ SD. In Europe, instead, the European Medicines Agency (EMA) has not extensively approved rGH therapy in ISS and treatment can be only addressed locally to selected patients and under specific circumstances. Although rGH therapy in ISS is yet a matter of debate, the dosages currently used are higher than the ones of GHD patients ${ }^{40}$ and allow, according to three randomized trials, an overall height gain of 1.20 SDS $(7.2 \mathrm{~cm})$ in treated children versus 0.34 SDS $(2.0 \mathrm{~cm})$ in untreated ones ${ }^{35}$. Thus, the dosages currently used in ISS can lead to question whether the results at AH in our patients belonging to Group B would have been superior with higher rGH doses, as in Group C. Indeed, lower dose rGH treatment in children who would otherwise be making their own pubertal growth spurt actually reduces pubertal growth attainment.

Moreover, based on our results, the reduction of the cut-off seems to be correlated with GHD persistence through transition, as previously found in another report, though using a different threshold $(\mathrm{GH}<5 \mathrm{ng} / \mathrm{mL})$. In this work, authors concluded that GH response at provocative tests could be a reliable predictor of persistent $\mathrm{GHD}^{41}$. Indeed, in literature it is reported that the $60-80 \%$ of patients with childhood-onset GHD re-test normal at provocative tests performed after discontinuation of treatment at $\mathrm{AH}$ attainment ${ }^{23-27}$. There are several potential causes of GH response normalization ranging from transient GHD, physiological improvement of hypothalamic-pituitary functions after puberty, NSD with a normal response to the provocative test but altered spontaneous release of $\mathrm{GH}$ or poor reproducibility of the $\mathrm{GH}$ provocative test ${ }^{42}$. According to our data, the percentage of persistent GHD in Group A $(28 \%)$ is consistent with the reported prevalence in literature. The lower percentage found in Group B (only 10\%), instead, leads to wonder whether all the patients in this Group were true GHD or instead ISS.

On the other hand, GH impairment due to hypothalamic derangement (NSD) is still a controversial issue. Given the complexity of the GH-IGF-I axis, a disruption at any level could result in abnormalities in GH secretion causing poor linear growth and short stature. Non-classical GHD due to NSD was firstly observed in cranio-irradiated children, broadening our understanding of GH deficiencies ${ }^{33}$. Even if the diagnosis of NSD in the absence of a history of cranial irradiation is uncommon, there are some patients with a clinical presentation 
strongly consistent with GHD that show a good response to rGH therapy, despite their stimulated GH peak being higher than the traditional cut-offs ${ }^{7}$.

In the present cohort, Group $\mathrm{C}$ showed a satisfactory response at $\mathrm{AH}$, better than Group $\mathrm{B}$, with all patients reaching MPH target at the end of treatment, even though initially treated with higher rGH dosages. Despite the fact that in patients diagnosed as NSD short-term acceleration of growth was observed in some reports, similar to that seen in children with conventionally defined $\mathrm{GHD}^{33,43,44}$, neither long-term growth nor AH data were presented. It should be pointed out that the first-year acceleration of height velocity can represent an unreliable predictor of HT gain at AH, especially when chronological age is consistent with pubertal onset and bone age is delayed. The only data available about NSD long-term response to $\mathrm{rGH}$ are found in one retrospective study by Radetti and colleagues that showed a mean HT gain of 1.03 SDS at AH, lower than patients with either subnormal levels at GH provocative tests and GH profile (1.85 SDS) but higher than patients with insufficient levels after pharmacological stimulation and normal GH profile $(0.49 \text { SDS })^{30}$.

Moreover, NSD represents one of the possible causes of GH secretion normalization at $\mathrm{AH}$ attainment. According to our results, as expected, the majority of patients showed a normal response to the GHRH + arginine test except one $(1 / 13,8 \%)$. In the presence of an underlying hypothalamic derangement, the GHRH + ariginine test is the one with the highest false negative rate, as observed in childhood cancer survivor patient ${ }^{45-47}$. It would be interesting to verify whether using another provocative test (i.e. ITT) the results would have been different.

Assuming the open issues about biochemical diagnosis of GHD, multiple regression analysis of our data confirmed the importance of the auxological criteria reported in literature ${ }^{48}$, as the better response was found in patients with severe short stature at baseline. The regression analysis high-lightened also the importance of rGH dosage, leading to question whether less severe GHD, as well as ISS, has to be treated with higher doses (at least $0.035 \mathrm{mg} / \mathrm{kg} /$ day) to show a long-term good response $\mathrm{s}^{35,49}$.

Moreover, $80 \%$ patients with persistent GHD at transition had anterior pituitary hypoplasia or partial empty sella, suggesting a possible predictive value of MRI findings. In particular, all the patients with persistent GHD of Group B and C had pituitary hypoplasia in accordance with previous data ${ }^{23}$, though literature has reported contrasting results on the topic ${ }^{41}$.

The present retrospective study has some limits: first of all, the relatively high median chronological age at diagnosis (11.9 years). In order to avoid biases related to delayed diagnosis, we analysed long-term outcomes in the subgroup of patients who were pre-pubertal at baseline. Even after that, it is possible an overlapping of GHD in constitutional delay of growth and puberty in our population, given the difficulties sometimes encountered in the differential diagnosis and the lack of an agreement on the use of sex hormone priming ${ }^{3}$. Secondly, given the wide span time of the study, it has been impossible to assess GH concentrations with the same assay, though in our central laboratory only one change occurred in 2007, as stated in the "methods" section.

Moreover, retesting has been performed with the use of GHRH + arginine in the vast majority of patients $(n=54)$ : this combined test represents one of the most powerful GH stimulation tests showing less intra-individual variability, but remains questionable in several patients, especially in the presence of primary hypothalamic dysfunction, as in childhood cancer survivors or NSD, as abovementioned ${ }^{50}$.

In conclusion, present data demonstrate that a reduction of diagnostic cut-off at GH stimulation tests, as suggested by the latest recommendations ${ }^{3}$, could better discriminate between "good" and "poor responders" and predict the persistence of GHD through transition. On the other hand, GHD diagnosis solely based on provocative tests could exclude patients that might benefit from rGH treatment. Low baseline IGF-I SDS and long-term outcomes in patients with normal stimulation test bring back to light NSD as a possible aetiology of ISS presenting a good response to therapy.

Received: 30 December 2020; Accepted: 18 June 2021

Published online: 15 July 2021

\section{References}

1. National Institute for Health and Clinical Excellence. Human growth hormone (somatropin) for the treatment of growth failure in children. Technology appraisal guidance. http://www.nice.org.uk/guidance/ta188.

2. Grimberg, A. et al. Drug and Therapeutics Committee and Ethics Committee of the Pediatric Endocrine. Guidelines for growth hormone and insulin-like growth factor-I treatment in children and adolescents: Growth hormone deficiency, idiopathic short stature, and primary insulin-like growth factor-I deficiency. Horm. Res. Paediatr. 86(6), 361-397 (2016).

3. Collett-Solberg, P. F. et al. Diagnosis, genetics, and therapy of short stature in children: A growth hormone research society international perspective. Horm. Res. Paediatr. 92(1), 1-14 (2010).

4. Savage, M. O., Burren, C. P. \& Rosenfeld, R. G. The continuum of growth hormone-IGF-I axis defects causing short stature: Diagnostic and therapeutic challenges. Clin. Endocrinol. (Oxf). 72(6), 721-728 (2010).

5. Kaplan, S.L., Abrams, C.A., Bell, J.J., Conte, F.A., Grumbach, M.M. Growth and growth hormone. I. Changes in serum level of growth hormone following hypoglycemia in 134 children with growth retardation. Pediatr. Res. 2, 43-63 (1968).

6. Murray, P. G., Dattani, M. T. \& Clayton, P. E. Controversies in the diagnosis and management of growth hormone deficiency in childhood and adolescence. Arch. Dis. Child. 101(1), 96-100 (2016)

7. GH Research Society. Consensus guidelines for the diagnosis and treatment of growth hormone (GH) deficiency in childhood and adolescence: Summary statement of the GH Research Society. J. Clin. Endocrinol. Metab. 85(11), 3990-3993 (2000).

8. Wilson, T. A. et al. Lawson Wilkins Pediatric Endocrinology Society Drug and Therapeutics Committee. Update of guidelines for the use of growth hormone in children: The Lawson Wilkins Pediatric Endocrinology Society Drug and Therapeutics Committee. J. Pediatr. 143(4), 415-421 (2003).

9. Tassoni, P. et al. Variability of growth hormone response to pharmacological and sleep tests performed twice in short children. J. Clin. Endocrinol. Metab. 71, 230-234 (1990).

10. Loche, S. et al. Growth hormone response to oral clonidine test in normal and short children. J. Endocrinol. Invest. 16, 899-902 (1993).

11. Maghnie, M. et al. Diagnosis of growth hormone deficiency: The value of short-term hypocaloric diet. J. Clin. Endocrinol. Metab. 77, 1372-1378 (1993). 
12. Rosenfeld, R. G. et al. Diagnostic controversy: The diagnosis of childhood growth hormone deficiency revisited. J. Clin. Endocrinol. Metab. 80, 1532-1540 (1995).

13. Ghigo, E. et al. Reliability of provocative tests to assess growth hormone secretory status: Study in 472 normally growing children. J. Clin. Endocrinol. Metab. 81, 3323-3327 (1996).

14. Rahim, A., Toogood, A. A. \& Shalet, S. M. The assessment of growth hormone status in normal young adult males using a variety of provocative agents. Clin. Endocrinol. 45, 557-562 (1996).

15. Carel, J. C. et al. Adult height after long-term treatment with recombinant growth hormone for idiopathic isolated growth hormone deficiency: Observational follow-up study of the French population-based registry. BMJ 325, 70-76 (2002).

16. Bereket, A. Diagnosis of growth hormone deficiency: The role of growth hormone (GH), insulin- like growth factor (IGF-I) and IGF-binding protein (IGFBP-3). J. Clin. Res. Pediatr. Endocrinol. 1(1), 23-35 (2009).

17. Note AIFA 39. http://www.agenziafarmaco.gov.it/content/nota-39.

18. Hilczer, M., Smyczynska, J., Stawerska, R. \& Lewinski, A. Stability of IGF-I concentration despite divergent results of repeated GH stimulating tests indicates poor reproducibility of test results. Endocr. Regul. 40, 37-45 (2006).

19. Loche, S. et al. Results of early reevaluation of growth hormone secretion in short children with apparent growth hormone deficiency. J. Pediatr. 140(4), 445-449 (2002).

20. Rose, S. R. et al. The advantage of measuring stimulated as compared with spontaneous growth hormone levels in the diagnosis of growth hormone deficiency. N. Engl. J. Med. 319, 201-207 (1988).

21. Donaldson, D. L., Hollowell, J. G., Pan, F. P., Gifford, R. A. \& Moore, W. V. Growth hormone secretory profiles: Variation on consecutive nights. J. Pediatr. 115, 51-56 (1989).

22. Zadik, Z., Chalew, S. A., Gilula, Z. \& Kowarsk, A. A. Reproducibility of growth hormone testing procedures: A comparison between 24-h integrated concentration and pharmacological stimulation. J. Clin. Endocrinol. Metab. 71, 1127-1130 (1990).

23. Maghnie, M. et al. Growth hormone (GH) deficiency (GHD) of childhood onset: Reassessment of GH status and evaluation of the predictive criteria for permanent GHD in young adults. J. Clin. Endocrinol. Metab. 84, 1324-1328 (1999).

24. Longobardi, S. et al. Reevaluation of growth hormone (GH) secretion in 69 adults diagnosed as GH-deficient patients during childhood. J. Clin. Endocrinol. Metab. 81, 1244-1247 (1996).

25. Wacharasindhu, S., Cotterill, A. M., Camacho-Hübner, C., Besser, G. M. \& Savage, M. O. Normal growth hormone secretion in growth hormone insufficient children retested after completion of linear growth. Clin. Endocrinol. 45, 553-556 (1996).

26. Tauber, M., Moulin, P., Pienkowski, C., Jouret, B. \& Rochiccioli, P. Growth hormone (GH) retesting and auxological data in 131 GH-deficient patients after completion of treatment. J. Clin. Endocrinol. Metab. 82, 352-356 (1997).

27. Aimaretti, G. et al. Retesting young adults with childhood-onset growth hormone (GH) deficiency with GH-releasing-hormoneplus-arginine test. J. Clin. Endocrinol. Metab. 85, 3693-3699 (2000).

28. Growth Calculator 4 . http://www.weboriented.it/gh4/.

29. Tanner, J. M. et al. Assessment of Skeletal Maturity and Prediction of Adult Height (TW2 Method) Vol. 2 (Academic Press, 1983).

30. Radetti, G. et al. Growth hormone secretory pattern and response to treatment in children with short stature followed to adult height. Clin. Endocrinol. 59, 27-33 (2003).

31. Maghnie, M. et al. Diagnosis of GH deficiency in the transition period: Accuracy of insulin tolerance test and insulin-like growth factor-I measurement. Eur. J. Endocrinol. 152(4), 589-596 (2005).

32. Corneli, G., Di Somma, C., Prodam, F., Bellone, J., Bellone, S., Gasco, V., Baldelli, R., Rovere, S., Schneider, H.J. Gargantini, L., Gastaldi, R., Ghizzoni, L., Valle, D., Salerno, M., Colao, A., Bona, G., Ghigo, E., Maghnie, M., \& Aimaretti, G. Cut-off limits of the GH response to GHRH plus arginine test and IGF-I levels for the diagnosis of GH deficiency in late adolescents and young adults. Eur. J. Endocrinol. 157, 701-708 (2007).

33. Spiliotis, B.E., August, G.P., Hung, W., Sonis, W., Mendelson, W., Bercu, B.B. Growth hormone neurosecretory dysfunction. A treatable cause of short stature. JAMA 251, 2223-2230 (1984).

34. Bercu, B. B., Shulman, D., Root, A. W. \& Spiliotis, B. E. Growth hormone (GH) provocative testing frequently does not reflect endogenous GH secretion. J. Clin. Endocrinol. Metab. 63(3), 709-716 (1986).

35. Deodati, A., \& Cianfarani, S. Impact of growth hormone therapy on adult height of children with idiopathic short stature: systematic review. BMJ 342, c7157 (2011).

36. Cole, T. J., Hindmarsh, P. C. \& Dunger, D. B. Growth hormone (GH) provocation tests and the response to GH treatment in GH deficiency. Arch. Dis. Child. 89, 1024-1027 (2004).

37. Rogol, A. D., Blethen, S. L., Sy, J. P. \& Veldhuis, J. Do growth hormone (GH) serial sampling, insulin-like growth factor-I (IGF-I) or auxological measurements have an advantage over GH stimulation testing in predicting the linear growth response to GH therapy?. Clin. Endocrinol. (Oxf). 58, 229-237 (2003).

38. Wilson, D. M. \& Frane, J. A brief review of the use and utility of growth hormone stimulation testing in the NCGS: Do we need to do provocative GH testing?. Growth Horm. IGF Res. 15(suppl A), S21-S25 (2005).

39. Pozzobon, G. et al. Growth hormone therapy in children: Predictive factors and short-term and long-term response criteria. Endocrine 66(3), 614-621 (2019).

40. Grimberg, A. et al. Drug and Therapeutics Committee and Ethics Committee of the Pediatric Endocrine Society. Guidelines for growth hormone and insulin-like growth factor-I treatment in children and adolescents: Growth hormone deficiency, idiopathic short stature, and primary insulin-like growth factor-I deficiency. Horm. Res. Paediatr. 86(6), 361-397 (2016).

41. Smyczyńska, J., Stawerska, R., Lewiński, A. \& Hilczer, M. Incidence and predictors of persistent growth hormone deficiency (GHD) in patients with isolated, childhood-onset GHD. Endokrynol. Pol. 65(5), 334-341 (2014).

42. Inzaghi, E. \& Cianfarani, S. The challenge of growth hormone deficiency diagnosis and treatment during the transition from puberty into adulthood. Front. Endocrinol. 4, 34 (2013).

43. Rochiccioli, P., Dechaux, E., Tauber, M. T., Pienkowski, C. \& Tiberge, M. Growth hormone treatment in patients with neurosecretory dysfunction. Horm. Res. 33(suppl 4), 97-101 (1990).

44. Hernandez, M. et al. Multicenter clinical trial to evaluate the therapeutic use of recombinant growth hormone from mammalian cells in the treatment of growth hormone neurosecretory dysfunction. Horm. Res. 35, 13-18 (1991).

45. Bjork, J., Link, K. \& Erfurth, E. M. The utility of the growth hormone (GH) releasing hormone-arginine test for diagnosing GH deficiency in adults with childhood acute lymphoblastic leukemia treated with cranial irradiation. J. Clin. Endocrinol. Metab. 90(11), 6048-6054 (2005).

46. Darzy, K. H. et al. The usefulness of the combined growth hormone (GH)-releasing hormone and arginine stimulation test in the diagnosis of radiation-induced GH deficiency is dependent on the post-irradiation time interval. J. Clin. Endocrinol. Metab. 88(1), 95-102 (2003)

47. Lissett, C. A., Saleem, S., Rahim, A., Brennan, B. M. D. \& Shalet, S. M. The impact of irradiation on growth hormone responsiveness to provocative agents is stimulus dependent: Results in 161 individuals with radiation damage to the somatotropic axis. J. Clin. Endocrinol. Metab. 86(2), 663-668 (2001).

48. Reiter, E. O., Price, D. A., Wilton, P., Albertsson Wikland, K. \& Ranke, M. B. Effect of growth hormone (GH) treatment on the near-final height of 1,258 patients with idiopathic GH deficiency: analysis of a large international database. J. Clin. Endocrinol. Metab. 91, 2047-2054 (2006).

49. Radetti, G., Buzi, F., Paganini, C., Pilotta, A. \& Felappi, B. Treatment of GH-deficient children with two different GH doses: Effect on final height and cost-benefit implications. Eur. J. Endocrinol. 148, 515-518 (2003). 
50. Patti, G., Noli, S., Capalbo, D., Allegri, A.M.E., Napoli, F., Cappa, M., Ubertini, G.M., Gallizia, A., Notarnicola, S., Ibba, A., Crocco, M., Parodi, S., Salerno, M., Loche, S., Garré, M.L., Tornari, E., Maghnie, M., Di Iorgi, N. Accuracy and limitations of the growth hormone $(\mathrm{GH})$ releasing hormone-arginine retesting in young adults with childhood-onset gh deficiency. Front. Endocrinol. (Lausanne) 10, 525 (2019).

\section{Author contributions}

G.R. drafted the manuscript and performed statistical analysis; I.C. collected patients' data; C.G., E.P. and F.G. critically revised the various drafts of the manuscript, read and approved the final version before submission; M.A. critically revised the manuscript, read and approved the final version before submission.

\section{Funding}

The research did not receive any specific grant from any funding agency in the public, commercial or not-forprofit sector.

\section{Competing interests}

The authors declare no competing interests.

\section{Additional information}

Correspondence and requests for materials should be addressed to G.R.

Reprints and permissions information is available at www.nature.com/reprints.

Publisher's note Springer Nature remains neutral with regard to jurisdictional claims in published maps and institutional affiliations.

(c) (1) Open Access This article is licensed under a Creative Commons Attribution 4.0 International License, which permits use, sharing, adaptation, distribution and reproduction in any medium or format, as long as you give appropriate credit to the original author(s) and the source, provide a link to the Creative Commons licence, and indicate if changes were made. The images or other third party material in this article are included in the article's Creative Commons licence, unless indicated otherwise in a credit line to the material. If material is not included in the article's Creative Commons licence and your intended use is not permitted by statutory regulation or exceeds the permitted use, you will need to obtain permission directly from the copyright holder. To view a copy of this licence, visit http://creativecommons.org/licenses/by/4.0/.

(C) The Author(s) 2021 